\title{
Evaluation of the Feasibility of the Use of Bamboo as Potential Reinforcement in Concrete Beams
}

\author{
Osuji S. O. ${ }^{1}$ and Kayode-Ojo N. ${ }^{2, *}$ \\ ${ }^{1,2}$ Department of Civil Engineering, University of Benin, Benin City, Edo State, Nigeria \\ Corresponding Author: *engrngozi@yahoo.com
}

\begin{abstract}
This study presents the evaluation of the feasibility of using bamboo as a potential reinforcement in concrete beams. To achieve this, absorption test, tensile tests on the bamboo; compressive test on concrete cubes were conducted. Three-point bending tests on concrete beams reinforced with bamboo were performed to identify their behaviour compared to steel reinforced concrete members. The result for the absorption test indicated that water absorption of bamboo is quite high. The bamboo absorbed about $25 \%$ of water of its saturated weight in just 24 hrs and increased number of nodes brought about increased absorption of water. It also showed that the bamboo from the top part of the culm absorbed more water than those from the bottom of the culm, with an increase of about 9\%. For the tensile tests all the bamboo specimens showed brittle failure at node, making the node the most critical section for failure under tensile stresses, which was also verified in the beam tests. The yield stress was $56.80 \mathrm{~N} / \mathrm{mm}^{2}$. In general, the test results indicated that bamboo reinforcement enhanced the load carrying capacity by approximately $200 \%$.
\end{abstract}

Keywords: Bamboo, Three-point bending tests, Absorption, Tensile tests, Compressive tests

\subsection{Introduction}

In most countries, concrete is widely used as the foundation for the infrastructure. Concrete is used largely because it is economical, readily available and has suitable building properties such as its ability to support large compressive loads. However, the use of concrete is limited because it has low tensile strength. For this reason, it is reinforced, and one of the more popular reinforcing bars (rebar) is steel (Salau et al., 2012). Steel has a relatively high tensile strength, as high as $792 \mathrm{~N} / \mathrm{mm}^{2}$, complementing the strength of concrete. It is available and affordable in most developed countries but unfortunately not in all parts of the world. In many countries, none or very little steel reinforcement is used in construction, which is evident from the crumbling of buildings.

Steel reinforcement at some point may no longer be available. Even today there exists a need for more economical and readily available substitute reinforcements for concrete. In some parts of the world many buildings are constructed only with concrete or mud-bricks. This is dangerous in case of seismic activity. These buildings have little hope of standing in the case of an earthquake. Steel reinforcement would be an ideal solution, but cost is a considerable problem. Scientists and engineers are constantly seeking for new materials for structural systems; the idea of using bamboo as possible reinforcement has gained popularity (Siddhpura et al., 2013).

The energy necessary to produce $1 \mathrm{~m}^{3}$ per unit stress projected in practice for materials commonly used in civil construction, such as steel or concrete, has been compared with bamboo. It was found that for steel it is necessary to spend 50 times more energy than for bamboo. The tensile strength of bamboo is very high and can reach $370 \mathrm{~N} / \mathrm{mm}^{2}$ (Bhonde et al., 2014). This makes bamboo an alternative to steel in tensile loading applications as the ratio of tensile strength to specific weight of bamboo is six times greater than that of steel. 
Recently, in the attention and response to global warming issues and sustainable society, the use of natural materials for manufacturing has become more active. Bamboo's low cost, fast growing, and broad distribution of growth, is expected to contribute significantly to earthquake-resistant construction and seismic retrofit technology in the developing countries (Steinfeld, 2001). In concrete, reinforcement is put in place to provide tensile strength, a property that concrete lacks. Therefore, if bamboo is to be used as concrete reinforcement, it is necessary to understand how bamboo behaves in tension.

The aim of this study is to determine the feasibility of using bamboo as reinforcement in concrete beams and will be providing a preliminary contribution toward the collection of the mechanical properties and behaviours of bamboo and bamboo reinforced beams. The objectives are:

i. To carry out water absorption rate test on bamboo

ii. To carry out tensile tests on bamboo

iii. To compare the elastic modulus and flexural strength of bamboo reinforced beams and steel reinforced beams.

This study will consider the bambusa vulgaris specie, seasoned and cut into thin strips and tested without any treatment to determine the absorption and tensile properties of the bamboo. To examine the behaviour of the bamboo in the concrete, three-point load bending test will be conducted on bamboo reinforced beams and the results compared with that of steel reinforced and plain concrete beams.

This study is performed mainly for the rural areas, where bamboo is of ample amount, steel is rare, expensive or transportation cost is high. In coastal areas, the economic condition of people is very poor. In such type of backward area, such study may be essential for their development as well as an assurance for low cost housing. After the study it is seen that samples constructed as aid of bamboo can offer respectable amount of strength that can be safely used for low-cost housing.

The use of bamboo as a structural element may contribute to the reduction of material-based energy use of a structure (Sakaray et al., 2012). Even with the rising rate of insurgency around the globe, bamboo can be used to construct low cost but befitting structures for displaced individuals and families. The main obstacle for the application of Bamboo as a reinforcement is the lack of sufficient information about its interaction with concrete, strength and durability, hence the relevance of this work cannot be over emphasized.

\subsection{Materials and Methods}

The bamboos used for this study were very matured and cut from the undeveloped Site B section of the University of Benin, Benin City, Edo State in Nigeria. They were dried under the sun for thirty days before reducing to thin strips for the tests. The following tests were carried out:

\subsection{Absorption test}

Bamboo like wood changes its dimension when it loses or gains moisture. Bamboo is a hygroscopic material, tending to absorb moisture from air and surroundings (Wakchaure,and Kute, 2012). Four different bamboo splints were taken from top and bottom portions of bamboo culm for the test as shown in the Figure 1, with their properties listed in Table 1. 


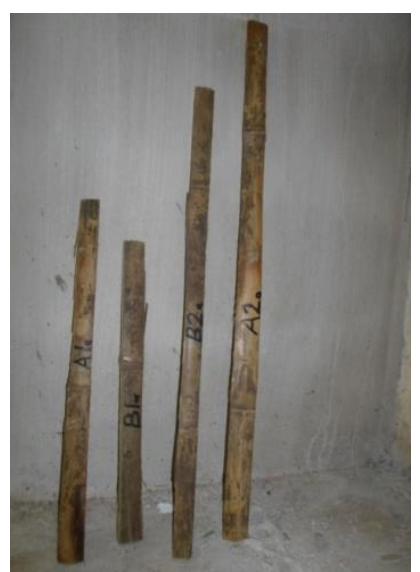

Figure 1: Absorption test specimen

Table 1: Description of absorption test specimen

\begin{tabular}{|l|l|}
\hline Specimen & Property \\
\hline $\mathrm{A} 1_{\mathrm{a}}$ & One internode (from top of culm) \\
\hline $\mathrm{A} 2_{\mathrm{a}}$ & Two internodes (from top of culm) \\
\hline $\mathrm{B} 1_{\mathrm{a}}$ & One internode (from bottom of culm) \\
\hline $\mathrm{B} 2_{\mathrm{a}}$ & Two internodes (from bottom of culm) \\
\hline
\end{tabular}

Using the below mathematical expression the amount of water absorbed by both types of samples was calculated.

$$
\begin{aligned}
& \text { Water absorbed }(\mathrm{gm})=\text { final saturated weight }(\mathrm{gm})-\operatorname{Dry} \text { weight }(\mathrm{gm}) \\
& \% \text { by weight of water absorbed }=\frac{\text { water absorbed }(\mathrm{gm})}{\text { final saturated weight }(\mathrm{gm})} \times 100
\end{aligned}
$$

\subsection{Tensile test}

Tension test is the most basic type of mechanical test. It is easy to perform and relatively inexpensive compared to other tests. The stress- strain characteristics of bamboo is derived from the results of this tension test.

The Bamboo strips were of various lengths and thicknesses (see Table 2). The ends of the specimen were roughed at both ends to have better grip in Universal Testing Machine. The sample strip of the Bamboo is as shown in Figure 2.

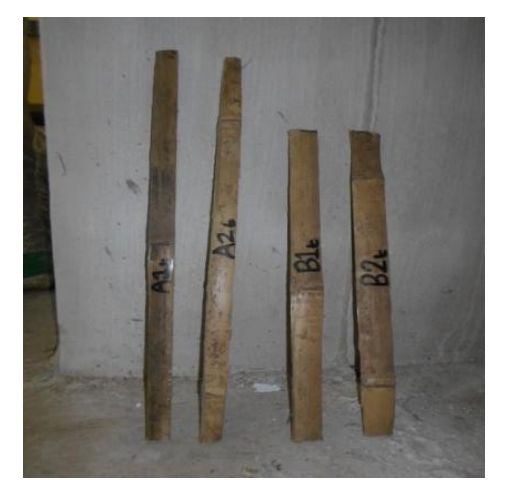

Figure 2: Tensile test specimen

Table 2: Description of tensile test specimen

\begin{tabular}{|l|l|l|l|l|l|l|}
\hline Sample & \multirow{2}{*}{ Node position } & \multicolumn{2}{|c|}{ Specimen size } & \multicolumn{3}{|l|}{ Cross sectional area } \\
\cline { 3 - 7 } & & Length $(\mathrm{mm})$ & Thickness $(\mathrm{mm})$ & End A & End B & Average $\operatorname{area}\left(\mathrm{mm}^{2}\right)$ \\
\hline $\mathrm{A} 1_{\mathrm{t}}$ & Centre & 540 & 10 & 220 & 230 & 225 \\
\hline $\mathrm{A} 2_{\mathrm{t}}$ & End & 540 & 10 & 220 & 190 & 205 \\
\hline $\mathrm{B} 1_{\mathrm{t}}$ & Centre & 450 & 15 & 450 & 420 & 435 \\
\hline $\mathrm{B} 2_{\mathrm{t}}$ & End & 450 & 15 & 420 & 450 & 435 \\
\hline
\end{tabular}


The position of the Bamboo strip in UTM is as shown in Figure 3.

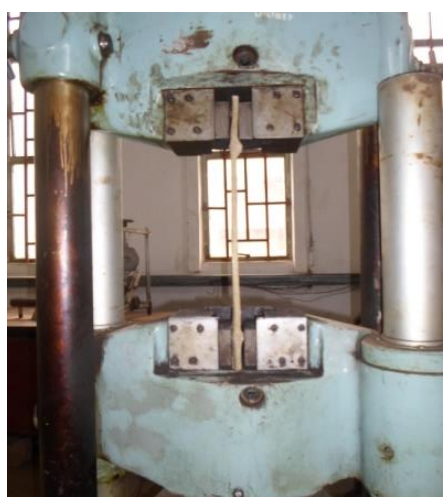

Figure 3: Bamboo strip in UTM

A stress vs strain curve was drawn from the results of the tensile test on the strip. The yield stress is also got from the stress vs strain curve.

The equation to calculate the Modulus of Elasticity is as mentioned in Equation 3.

$E=\frac{\sigma}{\varepsilon}$

where:

$\sigma \quad$ Stress

$\varepsilon \quad$ Strain

E Modulus of Elasticity

\subsection{Beam tests}

Since it is the purpose of this research to determine the feasibility of the use of Bamboo as reinforcement in concrete, it is necessary to compare its behaviours to steel, which is the traditional reinforcement. Therefore, beam designs were in accordance with BS 1881-118:1983 codes and specifications.

The dimensions were those that would allow for practicality of testing and construction, therefore a width of $150 \mathrm{~mm}$ and a depth of $150 \mathrm{~mm}$ was chosen for the test beam.

The next step was to determine the length of the beam. Evaluating the laboratory conditions and desired testing set-up, a beam length of $750 \mathrm{~mm}$ was chosen. Figure 4 shows the final dimensions of the test beam.

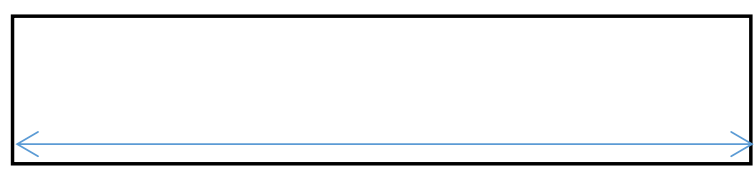

$750 \mathrm{~mm}$

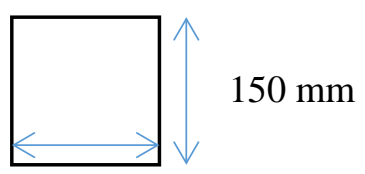

$150 \mathrm{~mm}$

Figure 4: Beam dimension

\subsection{Flexural test}

The Universal Testing Machine (UTM) was used for this test. The test set-up was done according to BS1881-118 1983.

The flexural strength $F_{c f}$ (in $\mathrm{N} / \mathrm{mm}^{2}$ ) is given by the equation:

$F_{c f}=\frac{(F \times L)}{\left(d_{1} \times d_{2}^{2}\right)}$ 
where:

$\begin{array}{ll}F & \text { Breaking load (in N); } \\ d_{l} \text { and } d_{2} & \text { Lateral dimensions of the cross-section (in mm); } \\ L & \text { Distance between the supporting rollers (in } \mathrm{mm} \text { ). }\end{array}$

From the results got from the test, a load vs deflection graph was plot and the elastic modulus of each kind of beam was calculated from the formula:

$E=\frac{\left[23 \times W \times L^{3}\right]}{[648 \times \delta \times I]}$

where:

W Load

$L \quad$ Length of the beam

$\delta \quad$ Deflection

I Moment of inertia.

Now,

$I=\frac{b d^{3}}{12}$

where:

$b \quad$ Width of the beam

$d \quad$ Depth of the beam

\subsection{Results}

\subsection{Absorption test result}

The absorption test result is shown in Table 3 below, while the graph showing the relationship between percentage of water absorbed and number of nodes is shown in Figure 5.

Table 3: Absorption test result

\begin{tabular}{|l|l|l|l|l|l|}
\hline Specimen & No. of nodes & Dry weight (g) & Saturated weight (g) & $\begin{array}{l}\text { Water absorbed after } \\
24 \mathrm{hrs}(\mathrm{g})\end{array}$ & $\begin{array}{l}\text { \% of water absorbed } \\
\text { (by sat. wt.) }\end{array}$ \\
\hline A1 & 1 & 55 & 72 & 17 & $23.61 \%$ \\
\hline A2 & 2 & 115 & 155 & 40 & $25.81 \%$ \\
\hline B1 & 1 & 115 & 135 & 20 & $14.81 \%$ \\
\hline B2 & 2 & 150 & 180 & 30 & $16.67 \%$ \\
\hline
\end{tabular}

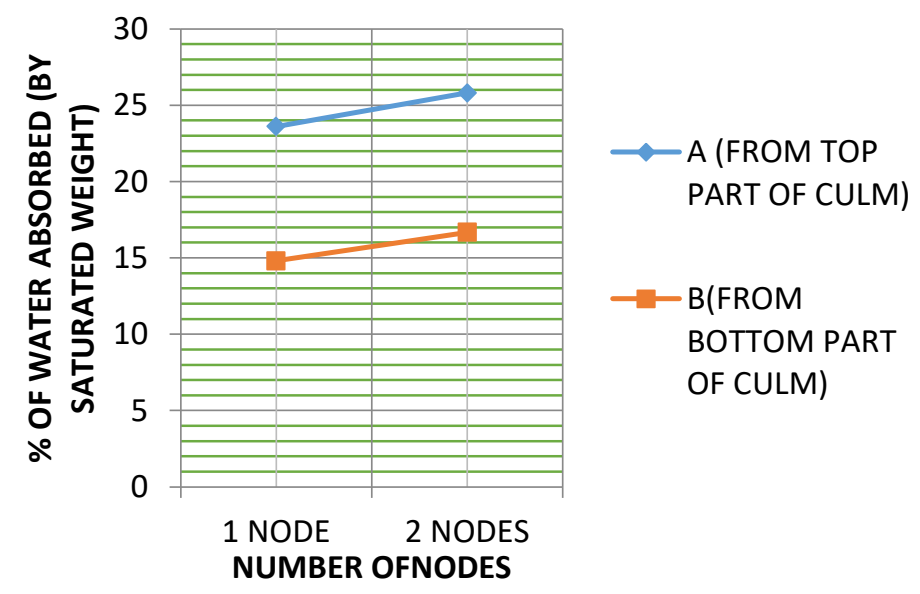

Figure 5: Graph of \% of water absorbed vs number of nodes 
Figure 5 shows that specimen with higher number of nodes absorbed a larger amount of water. The water absorption capacity of bamboo from the top of the culm is higher than that from the bottom of the culm. We see an additional increase of about $9 \%$.

Generally, from the experiment done, it is seen that the water absorption capacity of bamboo is high ranging to about $25 \%$ of saturated weight in just $24 \mathrm{hrs}$. This shows that there is a high possibility of swelling of the bamboo splints once they absorb water from the surrounding, eventually generating additional stresses in reinforced concrete elements if used as reinforcing material. It could also absorb and reduce a part of the water added in the concrete mix for hydration reactions and when the concrete becomes dry the bamboo splints contracts and creates spaces between the bamboo and concrete and the bamboo-concrete bond strength decreases and member fails in bond.

\subsection{Tensile test result}

Tensile tests were conducted on bamboo samples from different part of the culm and with different nodal position to find a pattern of behaviour based on the structure of Bamboo as a plant. The result of the tensile test (shown in Table 4) showed a pattern of failure. The samples failed at the node. Figure 6 shows four different test specimens after failure at the nodes.

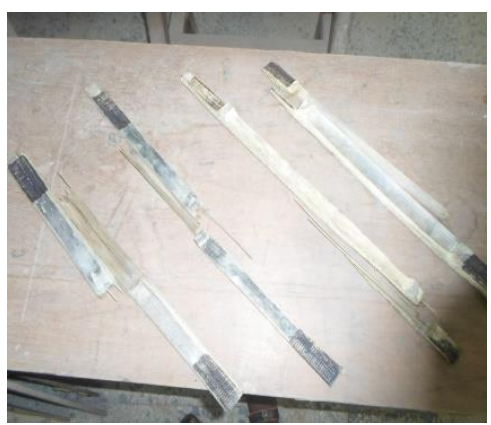

Figure 6: Failure patterns of bamboo specimens.

It was also observed that the samples with centre nodes held a larger load before reaching failure in contrast to those without a node. Examination of the node structure shows that the fibres in the nodes are much denser than those of the internodal regions. Also, the fibres which are straight elsewhere become chaotic in the node. Tests and study of Bamboo nodes indicate that the node may be very brittle and stiff, suggesting the reason why the specimen fails at the nodes. Test sample suggested the internodal regions of the Bamboo elongated until it reached a limiting value and then the load was transferred to the node.

The test results also showed that samples from the bottom of the culm generally held larger load before failure in contrast to those from the top part of the culm.

Table 4: Tensile test result

\begin{tabular}{|l|l|l|l|l|l|l|}
\hline Sample & $\begin{array}{l}\text { Failure Load } \\
(\mathrm{N})\end{array}$ & CSA $\left(\mathrm{mm}^{2}\right)$ & $\mathrm{L}(\mathrm{mm})$ & $\Delta \mathrm{L}(\mathrm{mm})$ & $\begin{array}{l}\text { Stress } \\
\left(\mathrm{N} / \mathrm{mm}^{2}\right)\end{array}$ & Strain \\
\hline $\mathrm{A} 1_{\mathrm{t}}$ & 18000 & 225 & 540 & 10 & 80.00 & 0.0185 \\
\hline $\mathrm{A} 2_{\mathrm{t}}$ & 16000 & 205 & 540 & 9 & 78.05 & 0.0167 \\
\hline $\mathrm{B} \mathrm{t}_{\mathrm{t}}$ & 37000 & 435 & 450 & 15 & 85.06 & 0.0333 \\
\hline $\mathrm{B} 2_{\mathrm{t}}$ & 34000 & 435 & 450 & 13 & 78.16 & 0.0289 \\
\hline
\end{tabular}

A sample test result is summarized in Figure 7. 


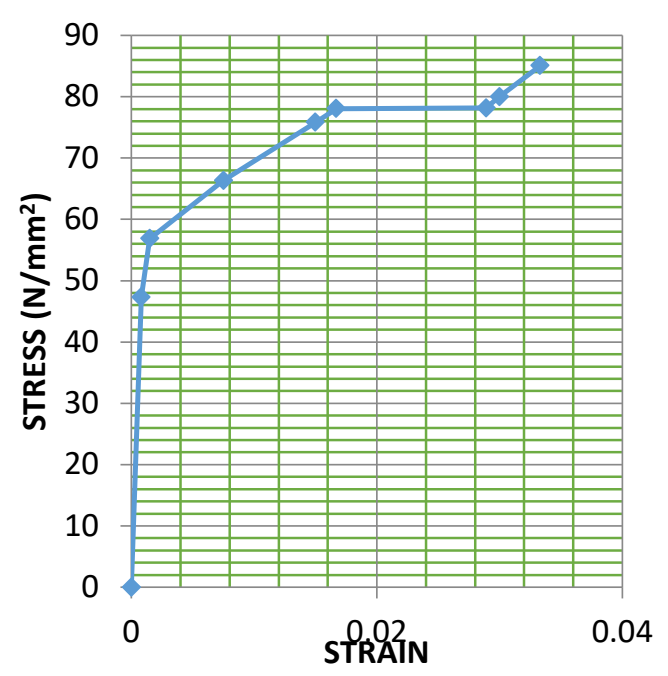

Figure 7: Graph of stress vs strain

It seems that constitutive relationship of the nodes differs from those of internodal regions with nodes having a brittle behaviour while internodal regions exhibit a more ductile behaviour. However, the ultimate strength of the node is anticipated to be higher than other regions.

The yield stress of the Bamboo strip is $56.80 \mathrm{~N} / \mathrm{mm}^{2}$.

The modulus of elasticity is calculated as follows:

$E=\frac{\sigma}{\varepsilon}$

$\sigma=56.80 \mathrm{~N} / \mathrm{mm}^{2}, \varepsilon=0.0015$.

Thus,

$E=56.80 / 0.0015$

$E=37,866.667 \mathrm{~N} / \mathrm{mm}^{2}$

The Modulus of Elasticity of the Bamboo strip is $37,866.667 \mathrm{~N} / \mathrm{mm}^{2}$.

\subsection{Flexural test result}

The beam was carefully placed under the testing machine and supports were placed at the measured location of $150 \mathrm{~mm}$ inside from each end. After placing the beam, one point loading at the mid-span of the beam was applied gradually. The deflection of the beam at mid- span was measured at regular interval of loading. From the experimental test the load deflection graph, ultimate carrying capacity and the type of failure were recorded.

\subsection{Comparison of modulus of elasticity of singly reinforced and doubly reinforced Bamboo beams}

Based on the experimental study the modulus of elasticity of Doubly Reinforced Beam is about $160 \%$ that of the Singly Reinforced Beam (see Table 5). The comparison is also shown in Figure 8. Modulus of elasticity for Singly Reinforced Beam is $8,246.04 \mathrm{~N} / \mathrm{mm}^{2}$. Modulus of elasticity for Doubly Reinforced Beam without steel stirrup is $12,422.84 \mathrm{~N} / \mathrm{mm}^{2}$ and with steel stirrup is $13,094.81 \mathrm{~N} / \mathrm{mm}^{2}$. 
Table 5: Modulus of elasticity and flexural strength for the different types of beams

\begin{tabular}{|l|l|l|l|l|}
\hline & Load, W(KN) & Deflection, $\delta(\mathrm{mm})$ & $\begin{array}{l}\text { Modulus of elasticity, E } \\
\left(\mathrm{N} / \mathrm{mm}^{2}\right)\end{array}$ & $\begin{array}{l}\text { Flexural strength, } \\
\mathrm{F}_{\mathrm{cf}}\left(\mathrm{N} / \mathrm{mm}^{2}\right)\end{array}$ \\
\hline Plain concrete & 18 & 0.87 & $7,343.6$ & 2.4 \\
\hline $\begin{array}{l}\text { Singly reinforced with } \\
\text { bamboo }\end{array}$ & 23 & 0.99 & $8,246.04$ & 3.1 \\
\hline Singly reinforced with steel & 50 & 1.08 & $16,432.33$ & 6.7 \\
\hline $\begin{array}{l}\text { Doubly reinforced with } \\
\text { bamboo without stirrups }\end{array}$ & 35 & 1.00 & $12,422.84$ & 4.7 \\
\hline $\begin{array}{l}\text { Doubly reinforced with } \\
\text { steel without stirrups }\end{array}$ & 59.8 & 1.12 & $18,951.17$ & 8.0 \\
\hline $\begin{array}{l}\text { Doubly reinforced with } \\
\text { bamboo with steel stirrups }\end{array}$ & 38 & 1.03 & $13,094.81$ & 5.1 \\
\hline $\begin{array}{l}\text { Doubly reinforced with } \\
\text { steel with steel stirrups }\end{array}$ & 62 & 1.15 & $19,135.80$ & 8.3 \\
\hline
\end{tabular}

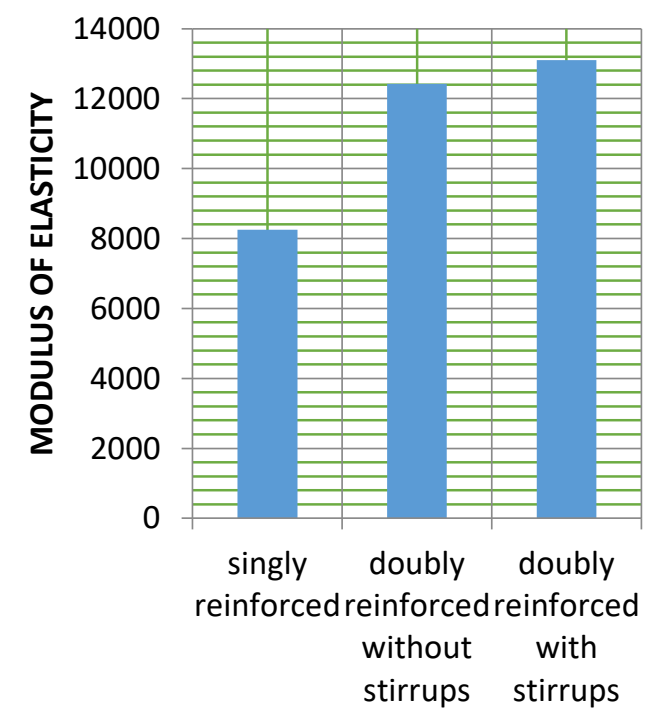

Figure 8: Comparison of modulus of elasticity for Bamboo reinforced beams

\subsection{Conclusion}

This work provides bamboo as a potential reinforcement in concrete beams. Bamboo has excellent engineering properties and can be utilized for low cost housing project. It can mainly be used as reinforcement to the structure. Drawback of bamboo as construction material is its water absorption and moisture content properties. This mainly affects its strength. To reduce this effect, seasoning and proper coating to bamboo should be done before using it for reinforcement. After the experiment, the following conclusions were made:

1. Water absorption of bamboo is quite high. To reduce this effect, seasoning or other suitable treatment should be given.

2. Tensile strength of bamboo is good and can be used as reinforcement in R.C. structure for low cost housing project. From stress-strain curves of bamboo, it can be seen that bamboo possesses low modulus of elasticity compared to steel. So, it cannot prevent cracking of concrete under ultimate load. But from the flexural test of bamboo reinforced beam, it has been seen that using bamboo as reinforcement in concrete can increase the load carrying capacity of beam having the same dimensions.

3. The stress-vs.-strain curve of bamboo splint in tension shows that bamboo is a visco elastic material having both viscous and elastic properties and exhibits time dependent strain elasticity.

4. Bamboo shows ductile behaviour as in steel. Hence it can be used as compression members in steel as well as R.C. structure.

5. For bamboo reinforced concrete beam, the load carrying capacity increased about 2 times that of plain concrete beam having same dimensions. 
6. The flexural strength of bamboo reinforced beam increases as high as nearly doubled compared to the plain concrete beam, so bamboo reinforced beam can be used in low cost buildings.

7. The maximum deflection of bamboo reinforced concrete beam is about 1.5 that of plain concrete.

This study concludes that it is possible to use bamboo as reinforcing for masonry structure.

\section{References}

Bhonde, D., Nagarnaik, P. B., Parbat, D. K. and Waghe, U. P. (2014). Experimental investigation of bamboo reinforced concrete slab. American Journal of Engineering Research 3(1), pp. 128-131.

BS 1881-183:1983 Testing concrete. Method for determination of flexural strength. BSI, Brussels.

Sakaray, H., Vamsi Krishna Togati, N.V. and Ramana Reddy, I.V. (2012). Investigation on properties of bamboo as reinforcing material in concrete. International Journal of Engineering Research and Applications, 2, pp. 1-5.

Salau, M.A., Adegbite, I. and Ikponmwosa, E.E. (2012). Characteristic strength of concrete column reinforced with bamboo strips. Journal of Sustainable Development, 5(1), pp. 133-143.

Siddhpura, N.B., Deep B.S., Kapadia, J.V., Chetan, S.A. and Sevalia, J.K. (2013). Experimental study on flexural element using bamboo as reinforcement. International Journal of Current Engineering and Technology 3(2), pp. 476-483.

Steinfeld, C. (2001). A Bamboo Future. Environmental Design and Construction. Available at: http://www.edcmag.com/CDA/ArticleInformation/features/BNP_Features_Items/

Wakchaure, M. R. and Kute, S.Y. (2012). Effect of moisture content on physical and mechanical properties of bamboo. Asian Journal of Civil Engineering (Building \& Housing) 13(6), pp. 753-763. 